American J. of Engineering and Applied Sciences 5 (1): 29-34, 2012

ISSN 1941-7020

(C) 2014 K.S.R. Mohan et al., This open access article is distributed under a Creative Commons Attribution

(CC-BY) 3.0 license

\title{
Properties of Fly Ash Based Coconut Fiber Composite
}

\author{
${ }^{1}$ Saravana Raja Mohan, K., ${ }^{2}$ P. Jayabalan and ${ }^{3}$ A. Rajaraman \\ ${ }^{1}$ School of Civil Engineering, Shanmugha Arts Science Technology and Research Academy, \\ Deemed University, Thanjavur-613 402 Tamil Nadu, India \\ ${ }^{2}$ Department of Civil Engineering, National Institute of Technology, \\ Tiruchirappalli-620 015 Tamil Nadu, India \\ ${ }^{3}$ Former Scientist, Structural Engineering Research Center, \\ Taramani, Chennai-600 036, India
}

\begin{abstract}
The present paper reports the results of a study undertaken in enhancing properties of fly ash concrete composites-FMCC with locally available natural fiber. In this context a composite with fly ash, concrete and treated coconut fibers-available in plenty in rural areas of India-can be a good proposition and with this background, experimental investigation to study the effects of replacement of cement (by weight) with different percentages of fly ash and the effects of addition of processed natural coconut fiber on flexural strength, compressive strength, splitting tensile strength and modulus of elasticity was taken up. A control mixture of proportions 1:1:49:2.79 with w/c of 0.45 was designed for the normally popular M20 concrete. Cement was replaced with five percentages (10, 15, 20, 25 and 30\%) of Class C fly ash. Four percentages of coconut fibers $(0.15,0.30,0.45$ and $0.60 \%)$ having $40 \mathrm{~mm}$ length were used. Test results show that the replacement of 43 grade ordinary Portland cement with fly ash showed an increase in compressive strength, splitting tensile strength, flexural strength and modulus of elasticity for the chosen mix proportion. Addition of coconut fibers resulting in fly ash mixed concrete composite -FMCCdid enhance the mechanical properties of FMCC and at the same time increased the energy levels reflected by increased failure strain, making the material suitable for seismic sustenance.
\end{abstract}

Key words: Concrete, coconut fibers, fly ash, mechanical properties

\section{INTRODUCTION}

In India, use of concrete in infra-structural activity is on the rise and with cement being the most important but costly component of concrete, effort to reduce cost by partial replacement of cement with fly ash has gained momentum and is even made as a government regulation. The utilization of fly ash instead of dumping it as a waste material can be both on economic and environmental grounds and also because of its beneficial effects of lower water demand for similar workability reduced bleeding and lower evolution of heat. The proportion of fly ash used as a cementitious component in concrete depends on several factors. The design strength and workability of concrete, water demand and relative cost of fly ash compared with cement are particularly important in mixture proportioning of concrete. The effects of fly ash type and content on the permeability characteristics of mortar materials subjected to two different curing conditions and two ages are presented in (Alhozaimy et al., 1996) and authors have concluded that as moist curing duration increased, the fly ash mortar became less permeable. High volume fly ash concrete has adequate early age and later age strength developments and considerably lower temperature rise and its applications should have a water content of not less than $115 \mathrm{~kg} \mathrm{~m}^{-3}$ and a sufficient amount of a retarded version of superplasticizer to maintain satisfactory slump and placing characteristics (Bisaillon et al., 1994). The effects of high temperature and high pressures on the strength and elasticity of concrete containing various levels of high calcium lignite fly ash and fixed percentage of silica fume are reported in the literature (Ghosh and Nasser, 1996). High volume fly ash concretes with fly ash/cementitious ratio upto $75 \%$ (by mass) and an aggregate ratio of 6 have compressive and flexural strengths that are more than adequate for lean concrete base or sub base application in pavement structure (Haque et al., 1984). One of the major

Corresponding Author: Saravana Raja Mohan, K., School of Civil Engineering, SASTRA University, Tirumalaisamudram, Thanjavur-613 402 Tamil Nadu, India Tel: 91-04362 264101-108 Extn. 112 Fax: 91- 04362264120 
developments in the area of fly ash utilization in concrete has been the technology of high performance, as demonstrated by use of high volume fly ash concrete by (Malhotra and Ramezanianpour, 1994; Malhotra, 1994). Siddique (2004) found that, with high volume of class ' $F$ ' fly ash, the workability of concrete increased and the cube compressive strength, split tensile strength, flexural strength decreased with significant effect on the impact strength of plain (control) concrete. Studies focusing on material properties with different percentage replacement of cement with fly ash are presented in (Saravanarajamohan et al., 2003) and on structural component with use of fly ash concrete and fiber concrete composites in (Goplakrishnan et al., 2001). Concrete containing 50\% replacement by mass of class $\mathrm{F}$ fly ash can be designed to have one-day and 28 day cube strengths of 20 and 60Mpa, respectively (Swamy, 1961). The use of fly ash in concrete is found to affect strength characteristics adversely. The reduction in strength can be retrieved to a large extent by adding processed natural fibers. In this study, an effort has been made to study the effects of natural coconut fibers on the property of FMCC. But studies focusing on application of this type of composites are very few and hence there is a need to assess the structural properties of fiber reinforced fly ash mixed concrete composites-FMCC-using different locally available natural and artificial fibers and this need is taken care of in this study with special reference to coconut fibers which is available in plenty in most of the coastal areas of India.

Experimental program: To bring into focus the use of coconut fibers in concrete, an experimental programme was planned to study the material characteristics and behaviour of structural components like beams. In this study, work on material properties is reported. In this experimental investigation, the structural properties of the coconut fiber reinforced concrete have been determined. The fiber concrete was prepared in various combinations of fiber length, fiber content and fly ash percentage as parameters. Specimens were prepared to study structural properties such as compressive strength, tensile strength, modulus of elasticity and modulus of rupture.

\section{MATERIALS AND METHODS}

Materials used: The constituent of materials used for making the concrete were tested and the results are furnished in Table 1. Tensile strength of the coconut fiber reinforced concrete was also tested. The cement, fine aggregate, coarse aggregate and fly ash were tested prior to the experiments and checked for conformity (ISI, 1965) with relevance to Indian standards (Bisaillon et al., 1994). Coconut fiber and fly ash were also tested to find their tensile strength and compressive strength. Figure 1 shows the view of coconut fiber used and the specimens tested.

Details of specimen: A nominal mix proportion of 1:1:49:2.79 with suitable water cement ratio was considered for this study. The exact quantity of materials for each mix was calculated. The parameters varied were fiber length, fiber content and fly ash percentage. The designation given for various mixes corresponding to fiber length, fiber content and fly ash percentage used for that particular mix are given in Table 2.

Table 1: Detail of constituent materials

\begin{tabular}{ll}
\hline Materials & Description \\
\hline Cement & Type- OPC 43 grade \\
Fly ash (\%) & Coal ash (class C), 10, 15, \\
& 20,25 and 30 \\
Fine aggregate & River sand falling on zone III, \\
& Fineness modulus of 2.5 \\
Coarse aggregate & 20 mm nominal size aggregate, \\
& Fineness modulus $=8.75$ \\
Coconut fiber & Diameter $=1 \mathrm{~mm}$, \\
& Tensile strength of \\
Fiber length & Coconut fiber $=160 \mathrm{MPa}$ \\
& $20,40,60,80 \phi=1 \mathrm{~mm}$ \\
Grade of concrete and W/C ratio & Aspect ratio- $(20),(40),(60),(80)$ \\
\hline
\end{tabular}

Table 2: Details of fiber and fly ash parameters used in batches

\begin{tabular}{|c|c|c|c|c|c|c|}
\hline \multirow{2}{*}{$\begin{array}{l}\text { Coconut } \\
\text { fiber } \\
\text { length }\end{array}$} & \multirow{2}{*}{$\begin{array}{l}\text { Fly ash } \\
(\%)\end{array}$} & \multicolumn{5}{|c|}{ Fiber content in percentage by weight } \\
\hline & & 0.00 & 0.15 & 0.30 & 0.45 & 0.60 \\
\hline 20 & 10 & C10F0 & 0.15 & 70.30 & $10 \mathrm{~F} 0.45$ & C10F0.60 \\
\hline 40 & 15 & & & & & \\
\hline 60 & 20 & & & & & \\
\hline 80 & 25 & $\mathrm{C} 25 \mathrm{~F} 0$ & $\mathrm{C} 25 \mathrm{~F} 0.15$ & $\mathrm{C} 25 \mathrm{~F} 0.30$ & $\mathrm{C} 25 \mathrm{~F} 0.45$ & $\mathrm{C} 25 \mathrm{~F} 0.60$ \\
\hline
\end{tabular}

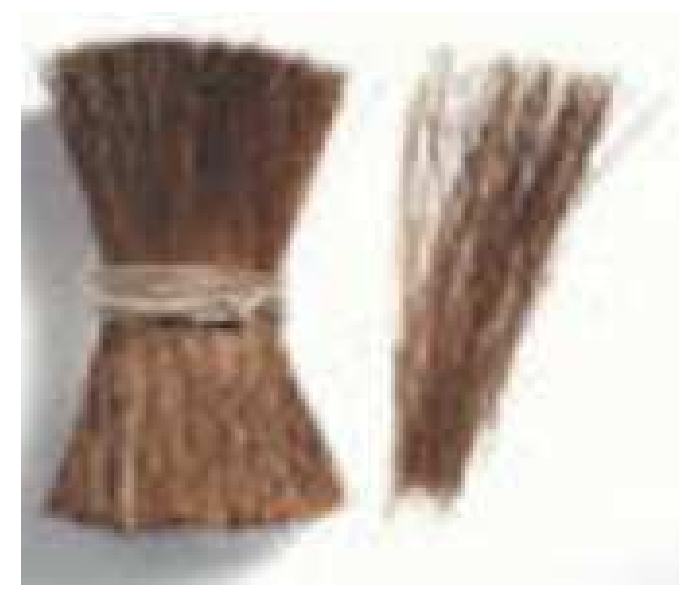

Fig. 1: Typical view of coconut fiber 
Table 3: Details of Specimens

\begin{tabular}{lll}
\hline Properties tested & Size in mm & $\begin{array}{l}\text { No. of } \\
\text { specimens }\end{array}$ \\
\hline 7 days cube compressive strength & $150 \times 150 \times 150$ & 3 \\
14 days cube compressive strength & $150 \times 150 \times 150$ & 3 \\
28 days cube compressive strength & $150 \times 150 \times 150$ & 3 \\
Cylinder compressive strength & $300 \times 150 \phi$ & 3 \\
Split tensile strength & $300 \times 150 \phi$ & 3 \\
Modulus of rupture [prism] & $500 \times 100 \times 100$ & 3 \\
\hline
\end{tabular}

Specimens were fabricated for various parameters to study their effect on the structural properties of concrete. The number of specimens fabricated, for studying various structural properties, is described in Table 3. Modulus of Elasticity was computed from the load deformation characteristics of the cylinder specimens.

Testing specimens: All the specimens were cast in oiled moulds, compacted using needle vibrators and cured for required period. These specimens were whitewashed before testing and tested under surface dry condition. Cubes and cylinders were tested using compression testing machine. Prisms were tested using universal loading frame.

\section{RESULTS}

The structural properties studied in this research are compressive strength, tensile strength and modulus of elasticity and modulus of rupture. The test results of the fiber reinforced concrete have been compared with plain concrete. From the photographs of the failed specimens shown in Fig. 2-4, it is clear that addition of fibers distributes the crushing and very rarely the aggregate is seen in the failed cubes and further fly ash addition does not change the pattern of failure significantly.

\section{DISCUSSION}

Cube compressive strength: The cubes and cylinders were tested for 7, 14 and 28 days. The maximum compressive strength was obtained for a mix having a fiber length of $40 \mathrm{~mm}, 10 \%$ fly ash and fiber content of $0.15 \%$ by weight and the increase in strength over plain cement concrete was found to be about $45.81 \%$.

The 7 day compressive strength of the fly ashbased fiber concrete was found to be as high as 18.95 $\mathrm{MPa}$, which is about $25.91 \%$ more than the ordinary concrete. Similarly 28 day compressive strength was found to be about $27.51 \mathrm{MPa}$ and is $45.81 \%$ more that of the ordinary concrete. The increase in cube compressive strength for fly ash-based fiber concrete with respect to the age is generally less than that of ordinary concrete.

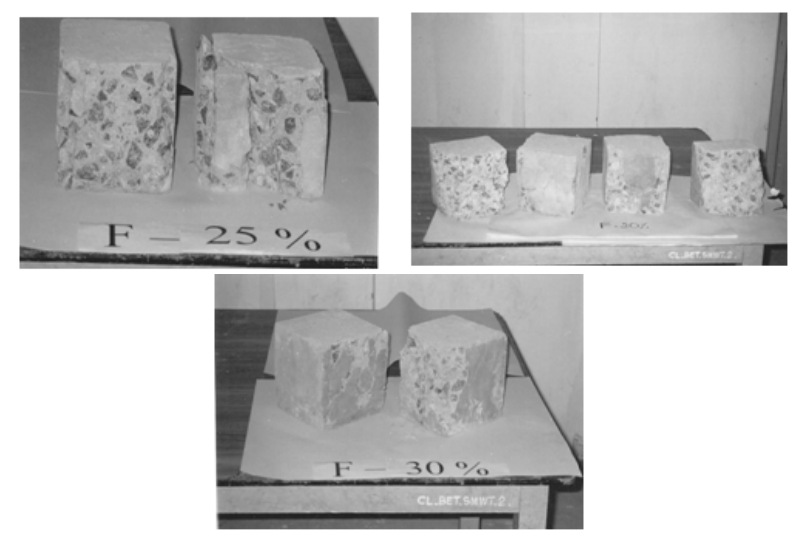

Fig. 2: Failure of cubes with fly ash only
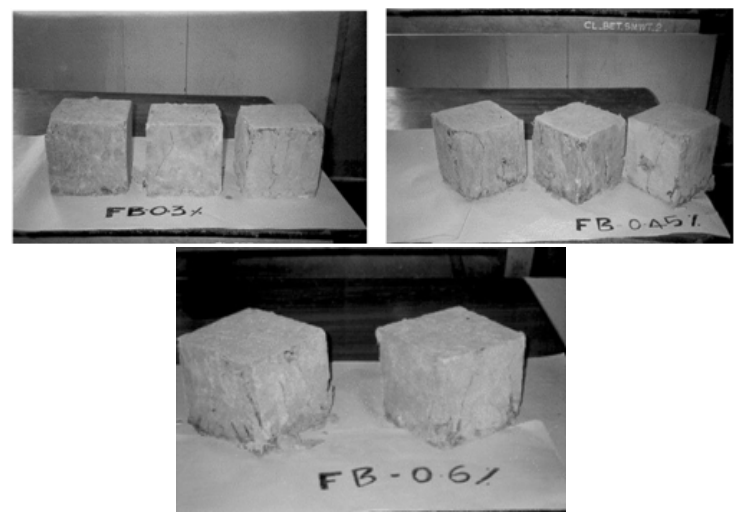

Fig. 3: Failure of cubes with fibers only
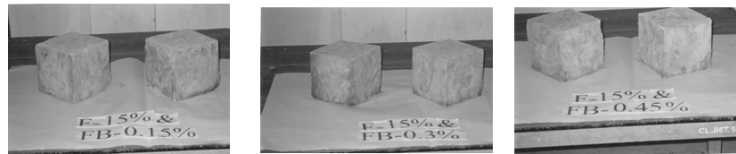

Fig. 4: Failure of cubes with fly ash and fibers

The effect of replacement of cement with five percentages of fly ash and addition of coconut fibers on the compressive strength of concrete is shown in Fig. 5. It is clear that the replacement of cement with 25 and $30 \%$ of fly ash reduced the compressive strength of concrete at 7 days by 8.5 and $25.31 \%$, respectively. And for a particular percentage of fly ash, there was a decrease in the compressive strength of fly ash concrete, as the percentage of fibers increased from $0.15-0.60 \%$. However, this reduction in strength with the addition of fibers continued to decrease with an increase in the percentage of fly ash content from 25$30 \%$. Generally, presence of fibers induces porosity and 
reduces the compressive strength. However, in this case, addition of fibers reduced the compressive strength between 2.2 and $25.31 \%$ depending on the fly ash content, which was not significant decrease, considering contribution of fibers in enhancing the tensile strength.

Cylinder compressive strength: The variation of cylinder compressive strength with respect to the fly ash percentage, fiber length and fiber content is given in Fig. 6. The maximum cylinder compressive strength is $23.68 \mathrm{MPa}$, which is about $26.97 \%$ more than the ordinary concrete. It is observed that the variation of cylinder compressive strength is very much similar to the cube compressive strength. This shows that the fiber bonding action during the failure of the cylinder specimens is identical with that of the cube specimens and also the fly ash based fiber concrete specimens maintained their structural integrity at all stages of loading.

Split-tensile strength tests: In each mix, three standard cylinder specimens were tested to determine the splitting tensile strength. The maximum value of splitting tensile strength obtained is $4.75 \mathrm{MPa}$, which is about $35.71 \%$ more than ordinary concrete. The maximum strength was obtained for a mix with fiber length $40 \mathrm{~mm}$, fiber content $0.30 \%$ by weight and $15 \%$ fly ash replacement of cement.

It is clear that the replacement of cement with 20 , 25 and $30 \%$ of fly ash reduced the splitting tensile strength of concrete by $18.57,22.14$ and $50 \%$, respectively. The variation of the splitting tensile strength with respect to fly ash percentage, fiber length and fiber content is given in Fig. 7. For a particular percentage of fly ash, there was an increase in the splitting tensile strength of fly ash concrete, as the percentage of fibers was increased from $0.15-60 \%$.

Modulus of rupture: The maximum Flexural strength obtained for coconut Fiber Reinforced Concrete was 4.65 MPa and that for Plain Cement Concrete was 4 $\mathrm{MPa}$. The corresponding strength improvement is $16.25 \%$. It was observed during testing that the ordinary concrete specimens failed without any warning, while the coconut fiber reinforced concrete specimens showed a ductile failure, giving ample warning.

The replacement of cement with 25 and $30 \%$ of fly ash reduced the flexural strength of concrete by 3.8 and $28.2 \%$, respectively. The flexural strength of concrete was determined for both ordinary concrete and fly ash fiber reinforced concrete composite.
The results of addition of coconut fibers on the flexural strength of fly ash concrete are shown in Fig. 8. Figure 8 shows that for a particular percentage of fly ash content, there was an increase in the flexural strength of fly ash concrete, as the percentage of fibers was increased from $0.15-0.65 \%$.

Modulus of elasticity: Modulus of elasticity was determined from the load deformation observation of the cylinder specimen. The variation of the modulus of elasticity value with respect to fly ash percentage, fiber length and fiber content is shown in Fig. 9. The modulus of elasticity of this composite significantly increases with respect to the fiber content and fly ash.

Based on these test results normalized curves were drawn for different materials over normal concrete. Figure 10 shows the normalized values of stress versus strain and it may be observed that even though the specimens show less $\mathrm{E}$ value their sustainability in terms of larger strains without failure prompt one to use these coconut fibers appropriately in specimens requiring larger flexibility or ductility.

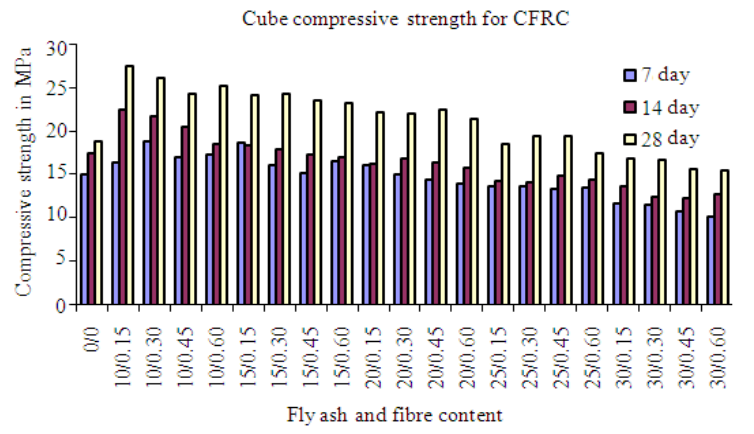

Fig. 5: Effect of Fly ash and fiber content on compressive strength

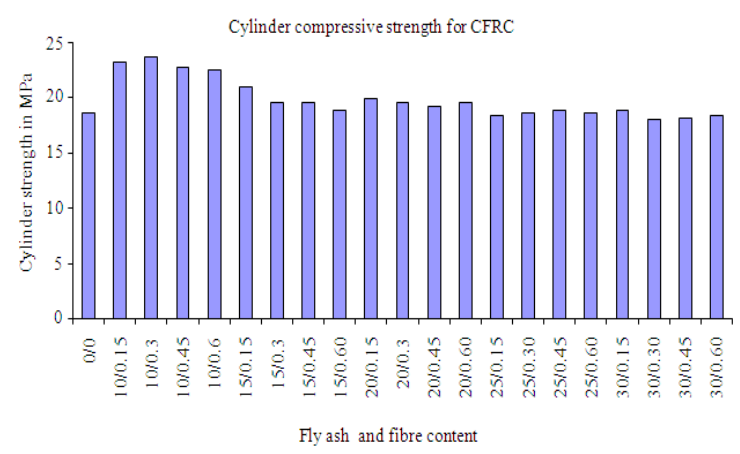

Fig. 6: Effect of fly ash and fiber content on cylinder compressive strength 


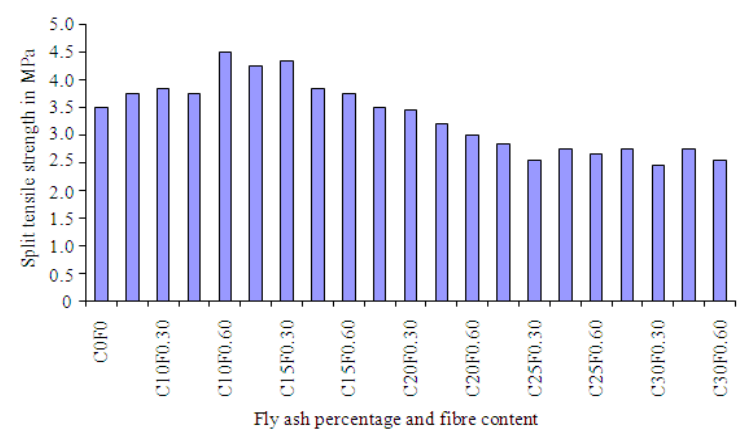

Fig. 7: Effect of fly ash and fiber content on split tensile strength

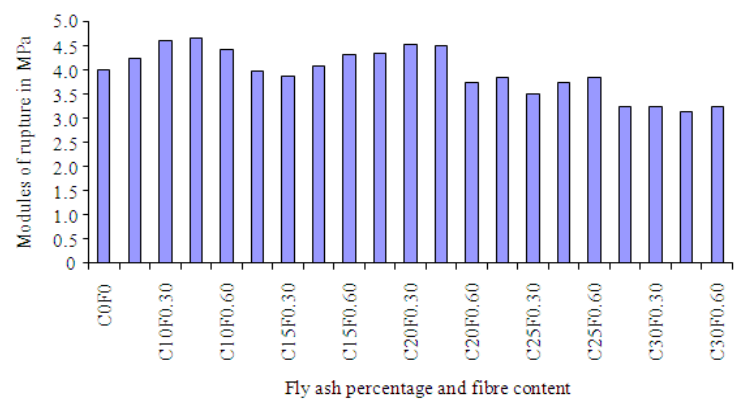

Fig. 8: Effect of fly ash and fiber content on modulus of rupture

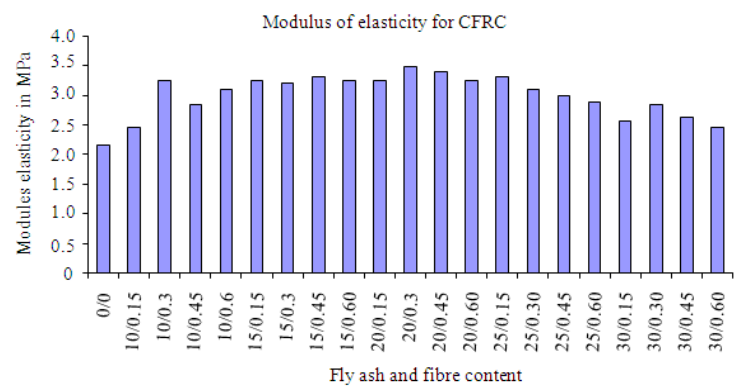

Fig. 9: Effect of fly ash and fiber content on modulus of elasticity

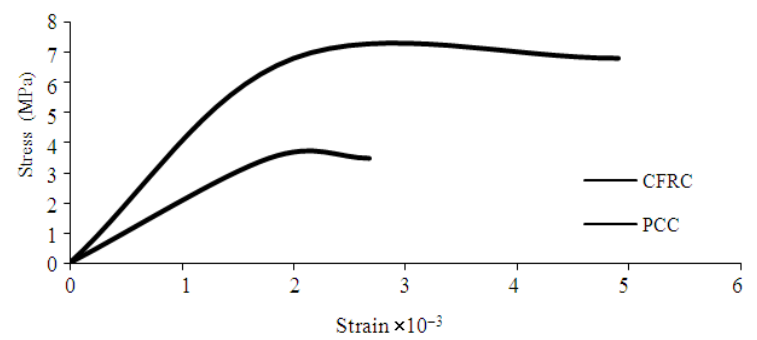

Fig. 10: Stress strain variation of composites with $15 \%$ fly ash and $0.15 \%$ fiber

\section{CONCLUSION}

Based on the results of investigation reported in this study, the following conclusions are drawn:

- The fly ash based Coconut fiber reinforced concrete shows a better performance than ordinary concrete

- Compressive strength of concrete was reduced by 8.5 and $25.31 \%$ for the replacement of cement with five percentages of fly ash mixed concrete. Addition of coconut fibers did not have significant effect on the compressive strength of fly ash concrete

- The splitting tensile strength of concrete decreased by $18.57,22.14$ and $50 \%$ with the replacement of cement with 20, 25 and $30 \%$ of fly ash. Addition of coconut fibers increased the splitting tensile strength of fly ash concrete, as the percentage of fibers was increased from $0.15-0.60 \%$

- Replacement of cement with the five percentages of fly ash reduced the flexural strength by 3.8 and $28.2 \%$ respectively. However, addition of coconut fibers marginally increased the flexural strength of fly ash concrete, as the percentage of fibers was increased from $0.15-0.60 \%$

- The replacement of fly ash up to $25 \%$ with coconut fiber resulted in a better performance under compression

- The 7 day compressive strength of composite having fly ash up to $25 \%$ is slightly less than that of the control concrete mix. But the compressive strength is marginally more than that of the control concrete mix at the age of 28 days

- The maximum 28 day cube compressive strength obtained was $27.51 \mathrm{MPa}$, for the mix with fiber length of $40 \mathrm{~mm}, 10 \%$ fly ash and fiber content $0.15 \%(18.86 \mathrm{MPa})$

- The maximum compressive strength of the cylinder obtained was $23.68 \mathrm{MPa}$, for the mix with fiber length of $40 \mathrm{~mm}, 10 \%$ fly ash and fiber content $0.30 \%\left(15.06 \mathrm{~N} \mathrm{~mm}^{-2}\right)$

- The maximum splitting tensile strength of the cylinder obtained was $4.75 \mathrm{MPa}$, for the mix with fiber length of $40 \mathrm{~mm}, 15 \%$ fly ash and fiber content $0.30 \%(3.5 \mathrm{MPa})$.

- The maximum value of modulus of elasticity obtained was $3.48 \mathrm{MPa}$, for the mix with fiber length of $40 \mathrm{~mm}, 20 \%$ fly ash and fiber content $0.30 \%$

- The stress and strain variation of coconut fiber composite is observed to show higher $\mathrm{E}$ value, 
their sustainability in terms of larger strains without failure prompt one to use these coconut fibers appropriately in specimens requiring larger flexibility or ductility

- The maximum value of flexural strength obtained was $4.65 \mathrm{~N} \mathrm{~mm}^{-2}$, for the mix with fiber length of $40 \mathrm{~mm}, 10 \%$ fly ash and fiber content $0.45 \%$

\section{REFERENCES}

Alhozaimy, A., P. Soroushian and F. Mizra, 1996. Effects of curing conditions and age on chloride permeability of fly ash mortar. ACI Mater. J., 93: 87-95.

Bisaillon, A., M. Rivest and V.M. Malhotra, 1994. Performance of high-volume fly ash concrete in large experimental monoliths. ACI. Mater. J., 91: 178-187.

Ghosh, S. and K.W. Nasser, 1996. Effects of high temperature and pressure on strength and elasticity of lignite fly ash and silica fume concrete. ACI. Mater. J., 93: 41-50.

Goplakrishnan, S., N.P. Rajamane, M. Neelamegam, J.A. Peter and J.K. Dattatreya, 2001. Effect of partial replacement of cement with flyash on the strength and durability of HPC. Indian Conc. J., 75: 335-346.
Haque, M.N., B.W. Langan and M.A. Ward, 1984. High fly ash concretes. ACI J. Proc., 81: 54-60.

ISI, 1965. Code of Practice for Plain and Reinforced Concrete. 1st Edn., Indian Standards Institution, New Delhi, pp: 109.

Malhotra, V.M. and A.A. Ramezanianpour, 1994. Fly Ash in Concrete. 2nd Edn., CANMET, Ottawa, Canada, ISBN: 0660157640, pp: 307.

Malhotra, V.M., 1994. Investigations dealing with high volume fly ash concrete-advances in concrete technology. CANMET, Ottawa.

Saravanarajamohan, K., P. Jayabalan and A. Rajaraman, 2003. Performance enhancement in concrete composites using local materials. Proceeding of the 28th International Conference on our World of Concrete and Structures, (ICWCS' 03), CI-Premier Ltd., Singapore, pp: 413-420.

Siddique, R., 2004. Properties of concrete incorporating high volumes of class F fly ash and san fibers. Cem. Conc. Res., 34: 37-42.

Swamy, R.N., 1961. Mineral admixtures for high strength concrete. Ind. Conc. J., 65: 265-271. 